\title{
Reviews
}

\section{No condition is permanent: the social dynamics of agrarian change in Subsaharan Africa, by Sara Berry; University of Wisconsin Press, 1993. xiv, 258 pp.}

\author{
Reviewed by Miriam S. Chaiken, Associate Professor and Chair, Department of \\ Anthropology, Indiana University of Pennsylvania.
}

Sara Berry has synthesized an impressive body of literature from history and anthropology, political economy, and policy to challenge the assumptions of many social theorists and development planners regarding the nature of African societies. The title is an indicator of her central thesis: the nature of both social institutions and individuals' networks and resources are in flux and highly variable. This necessary flexibility has precluded African farmers from participating in the "Green Revolution" and the improvements in agriculture that have affected many tropical farming systems. Additionally, she argues that these variable relations have prevented the political structure from totally capturing or controlling the African peasantry. Berry uses her personal research experiences and an extensive literature review to examine the dynamics of change in four African regions, the cocoa producing areas of Ghana and Nigeria, the Kenyan central highlands, and northeastern Zambia.

Berry begins the book with an overview of her thesis and an extremely coherent and useful summary of important models of economic theory and development. The balance of the book uses a temporal sequence to examine social dynamics during the precolonial and colonial periods, and the more recent patterns associated with the period of independence and planned economic development. She argues that the nature of the indigenous African societies was far more fluid than was commonly understood at the period of European contact. Despite the emphasis in the colonial period on uncovering the principles of "native law and custom" in the colonized cultures, administrators failed to recognize that most African societies were not characterized by highly rigid roles and laws, but rather interpersonal interactions were characterized by negotiation and manipulation of kin, economic, political, and social networks. The outcome of any negotiation, especially concerning usufruct land rights, was a product of an interplay of these varied factors and contemporary alliances and power struggles, not the result of highly codified legal principles.

With the imposition of colonial rule, specifically the patterns of Indirect Rule, this variability became even more pronounced. Rather than achieving order and regulation in legal relationships, the competing systems of European and traditional laws, and the varying interpretations of indigenous law and authority produced a system built on "conflict and change." Berry notes that highly effective individuals capitalized on this flux and often enhanced their positions, contributing to increasing socioeconomic differentiation and factionalism in African communities. The patterns of conflict were especially common in land tenure disputes and regarding policies governing the 
increasing commercialization of agriculture, both issues that are important for contemporary programs of economic development.

Independence did not resolve the conflict between competing jural systems. Instead, the growth of African bureaucracies and the struggles for power in the new political arenas further destabilized the economy of rural communities. The optimal strategy for many rural people was to increase the diversity of their social networks and clientage to cope with the instability of resource allocation, labor availability, and pricing. Berry argues that this has been a key factor in contributing to growing economic inequality and the frequent failure of development projects, regardless of efforts to be more inclusive, participatory, and culturally sensitive.

In her final chapter, Berry reiterates the odds facing the typical African farmer: often inadequate access to land or quality of landholdings, increasing problems in mobilizing labor, constraints to large-scale irrigation development, and general economic instability. She notes that many practices of African peasants decried by agricultural scientists and development planners--planting "uneconomic" crops (e.g. cassava), intercropping, investing in marginal petty trading--are strategies to increase flexibility and reduce risk for smallholders. In her conclusion, she notes that the possibilities for successful economic development hinge on planners' appreciation of this diversity, flexibility, and change that characterize African communities. Failure to address these issues will result in continued problems in programs of economic development. Berry has written a scholarly, persuasive volume that incorporates rich case study material to support her hypotheses.

Although the volume might be too dense to be easily accessible to undergraduates, it would be an appropriate reading for any scholar examining African development and certainly for advanced students. The book would be useful both as an ethnographic source for understanding the processes of change in the 20th century in the four study areas, and as a critique and analysis of colonial and postcolonial policies and economic planning in Africa. While primarily a historical source, the implications for future policy of Berry's work is clear, and the importance of her message unquestionable.

\title{
Ethnic Groups Across National Boundaries in Mainland Southeast Asia. Gehan Wijeyewardene, editor. Singapore: Institute of Southeast Asian Studies, 1990. viii, 192 pp.
}

\author{
Reviewed by Brian L. Foster, Dean, School of Arts and Sciences, University of \\ Nebraska.
}

As its title suggests, this book is about ethnic groups whose areas cross national boundaries. The editor's introduction promises, in fact, an analytical, or even theoretical, examination of how ethnic relations are related to special features of nation states-especially features that produce states' boundedness. This is an important and difficult set of issues, and the mountains of Mainland Southeast Asia provide an ideal vehicle for studying them--a variety of nations (China, Thailand, Burma, Laos, and Vietnam) with varying degrees of political stability, boundary integrity, degrees and modes of sociopolitical integration of ethnic minorities, and a bewildering variety of ethnic groups 